Article

\title{
Evaluation of Coatings to Improve the Durability and Water-Barrier Properties of Corrugated Cardboard
}

\author{
Andrea Marinelli ${ }^{1,2}{ }^{D}$, Maria Vittoria Diamanti ${ }^{1,2, * \mathbb{D}}$, Andrea Lucotti ${ }^{1}$, Maria Pia Pedeferri ${ }^{1,2}$ \\ and Barbara Del Curto ${ }^{1,2}$
}

1 Department of Chemistry, Materials and Chemical Engineering "Giulio Natta", Politecnico di Milano, Piazza Leonardo Da Vinci 32, 20133 Milan, Italy; andrea.marinelli@polimi.it (A.M.); andrea.lucotti@polimi.it (A.L.); mariapia.pedeferri@polimi.it (M.P.P.); barbara.delcurto@polimi.it (B.D.C.)

2 National Interuniversity Consortium of Materials Science and Technology (INSTM), Via Giuseppe Giusti 9, 50121 Firenze, Italy

* Correspondence: mariavittoria.diamanti@polimi.it; Tel.: +39-0223993137

check for updates

Citation: Marinelli, A.;

Diamanti, M.V.; Lucotti, A.; Pedeferri, M.P.; Del Curto, B. Evaluation of Coatings to Improve the Durability and Water-Barrier Properties of Corrugated Cardboard. Coatings 2022, 12, 10. https:// doi.org/10.3390/coatings12010010 Academic Editor: Douglas W. Bousfield

Received: 19 November 2021 Accepted: 18 December 2021 Published: 23 December 2021

Publisher's Note: MDPI stays neutral with regard to jurisdictional claims in published maps and institutional affiliations.

Copyright: (C) 2021 by the authors. Licensee MDPI, Basel, Switzerland. This article is an open access article distributed under the terms and conditions of the Creative Commons Attribution (CC BY) license (https:// creativecommons.org/licenses/by/ $4.0 /)$.

\begin{abstract}
Recently, corrugated cardboard furniture gained interest from the market, yet is limited to indoor application. With an aim toward outdoor usage, water-barrier improvement of such products must be achieved. In this work, three commercially available coating grades (i.e., polymeric, mineralfilled polymeric, and hybrid silica sol-gel products) were spray-coated on corrugated cardboard using a facile, yet readily transferable, process. The investigation assessed the coating performance from the different drying conditions and natural UV-vis weathering effects, characterising their water absorption, hydrophobicity, coating morphology, and colour change. Results show a reduction in water absorption values (up to $-98 \%$ ) for both the polymeric coatings; instead, the hybrid sol-gel coating showed contact angles up to almost $150^{\circ}$. Generally, the SEM micrographs displayed some surface defects as well as good thickness homogeneity. A perceivable colour change occurred for each sample (CIEDE2000 up to 6.41), mainly occurring in the $0-100 \mathrm{~h}$ time range. This work provides promising results for the outdoor application of corrugated cardboard furniture.
\end{abstract}

Keywords: spray coating; water barrier; corrugated cardboard; durability; natural weathering

\section{Introduction}

Corrugated cardboard is mainly used in packaging applications [1]. Due to the hydrophilic nature of cellulose, humidity and water strongly influence the properties of corrugated board products, hence the limits on their widespread use. Several studies reported solutions that implement water and moisture resistance of cellulosic substrates [2-10]. Generally, such properties are optimised via bulk or surface modification (i.e., chemical, physical, or coating). Hence, possible solutions include—among others-grafting, surface sizing, use of additives, layer deposition, etc. of the material ranging from polymers to minerals and oxides. Additionally, surface functionalisation of cellulosic substrates involves different industrial application technologies, e.g., lamination, extrusion coating, curtain coating, and spray-coating [11,12].

Recently, designers and design companies explored the use of corrugated cardboard for furnishing (CCF) and items of furniture [13,14]. Hence, temporary stores, expos, and homes witnessed increasing use, which enlarged the market share of CCF. However, indoor application is still a constraint. Coatings can improve the corrugated cardboard water barrier and wet performance. Multiple works were done in the literature to improve corrugated cardboard water barrier properties [15-20]. The proposed solutions that were typically investigated used pigments and polymers.

Current industrial applications for CCF impose several constraints in the material and technology choice, among which: 
- The technology, which should coat the product and its components all around. Since featuring the complex 3D geometries, the pieces of furniture sometimes highly expose the flutes, which require coating as well;

- $\quad$ The recycling process, which requires minimum coating amounts to limit the detrimental effects encountered at a paper mill [21,22];

- Industrial availability, since the companies look for commercially available and industrialised coating products.

Spray coating has the credentials to be the optimal solution for corrugated cardboard furniture, because:

- It is a contactless process, allowing the coating of both planar and curved surfaces, as well as the outermost part of the flutes;

- It minimises the use of coating products. Being that using CCF is usually a layer-bylayer assembly, spray coating the end product avoids putting coating application on overlapping surfaces (as it would occur in lamination, extrusion coating, etc.);

- It prevents the production waste from being coated. By coating the final products, cardboard sheets that become waste still maintain high economic value.

Some interesting work reported on the use of sol-gel spray technologies to coat cellulosic substrates $[23,24]$ and to obtain superhydrophobic substrates. However, small-scale systems and nozzle diameters lead to time-consuming processes when coating corrugated board furniture at an industrial scale.

In this work, corrugated cardboard was spray-coated using three available commercialgrade products. The aim was to assess their functional (both in terms of water barrier properties and durability) and aesthetic performance through time to enable the outdoor application for corrugated cardboard furniture. The facile methodology proposed aims to provide a readily available technological transfer to even low-technology companies. Additionally, the described setup may suit the (still) limited cardboard furniture production volumes. Such methodology may enable the outdoor application of CCF, thereby enhancing the cardboard durability in adverse environments-given its uncoated properties.

The study involved the variable drying conditions of the spray. A contact angle and Cobb1800 method determined the hydrophobic and water absorption performance, respectively. Moreover, the samples underwent natural UV-vis weathering, measuring colour change and surface morphology, while following the evolution of the hydrophobic and water-repellent properties. Lastly, actual products were coated and exposed to outdoor conditions in an urban environment, evaluating the qualitative performance of the investigated coatings over several months.

\section{Materials and Methods}

C-fluted triple-wall corrugated board (2200 g/ m², $20 \mathrm{~mm}$ thick, virgin kraft top liners) was kindly provided by Scatolificio Lariano (Italy). Three different commercially available water-based coating formulations were used:

- T-POL, a mineral-filled polymeric coating composed of polyethylene, polystyrene, carboxylated styrene-butadiene, and talc (see supplementary material);

- $\quad$ K-POL, a mineral-filled polymeric coating composed of styrene acrylic copolymer and kaolin (see supplementary material);

- SG, a fluorinated $\mathrm{SiO}_{2}$ sol-gel that involves a fluoroalkyl-functional water-borne oligosiloxane, featuring reactive silanol groups to bind with inorganic substrates, aminoalkyl-functional substituents to make it water-soluble, and fluoroalkyl-functional groups to achieve low specific surface energy.

UN-CA Design (Italy) kindly provided two corrugated cardboard stools made of the same triple-wall corrugated board used in this work. The investigation matrix is reported in Figure 1, which involves the different drying conditions, natural UV-vis weathering time, and the specific coating product applied. The control samples (i.e., uncoated samples) did not undergo oven drying conditions since they were not spray-coated. 


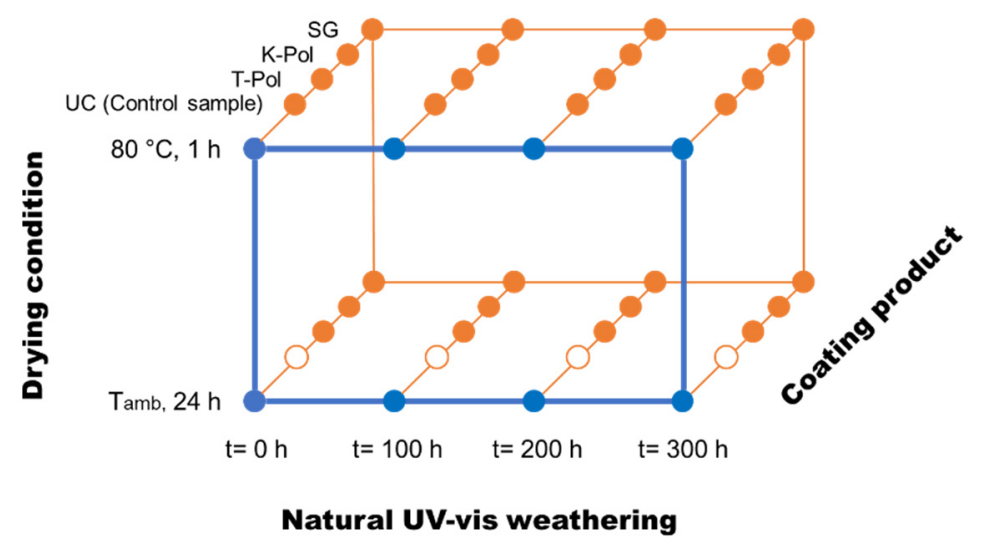

Figure 1. Investigation Matrix.

For the sake of clarity, the "X_Y" nomenclature was adopted, where " $\mathrm{X}$ " is the coating product (UC: uncoated; M-POL: talc-filled polymeric coating; K-POL: kaolin-filled poly-

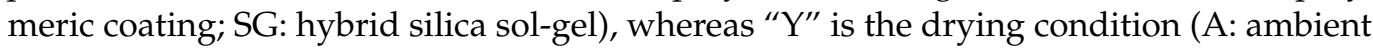
conditions; H: oven).

\subsection{Sample Preparation}

Samples measured $150 \mathrm{~mm} \times 150 \mathrm{~mm}$. Three unweathered samples were tested, while only one sample was prepared for the other conditions (i.e., weathering time: 100, 200 and 300 h).

The coating materials were used as provided, ensuring mechanical stirring with a magnetic anchor for $20 \mathrm{~min}$ at $250 \mathrm{rpm}$ prior to their use. In particular, SG was stirred at $650 \mathrm{rpm}$ for at least $4 \mathrm{~h}$ to ensure good dispersion of the colloidal suspension. Samples were spray coated using a High-Volume Low-Pressure (HVLP) spray gun featuring a $1.4 \mathrm{~mm}$ (diameter) nozzle. The inlet pressure was 3 bars, and the working distance was $0.15 \mathrm{~m}$. Manual spray coating of the samples occurred at ambient conditions, moving horizontally at a constant speed of $0.30-0.35 \mathrm{~m} / \mathrm{s}$.

Drying conditions were:

- $\quad$ Oven drying inside a Salvis Lab TC 100 oven at $80^{\circ} \mathrm{C}$ for $1 \mathrm{~h}$;

- Ambient drying at room temperature $\left(20-25^{\circ} \mathrm{C}, 20-40 \%\right.$ relative humidity) for at least $24 \mathrm{~h}$.

A schematization of the sample preparation procedure is reported in Figure 2.
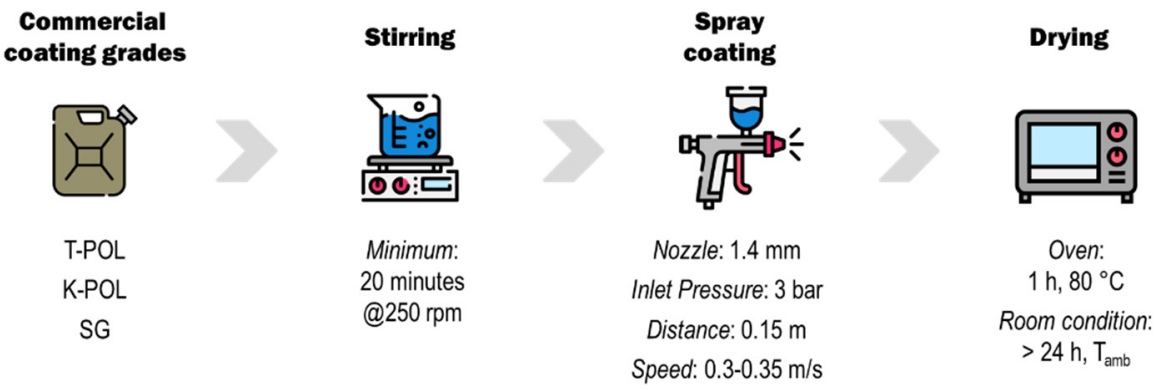

Figure 2. Schematisation for the facile spray-coating process.

\subsection{Natural Weathering}

Natural UV-vis weathering occurred on $45^{\circ}$ sloped racks (Figure 3 ) exposed to the south on a terrace (placed in Bovisa, Milan, Italy) on sunny or partly cloudy days in daylight conditions. During the nighttime, the samples were stored indoors in room conditions. Weathering occurred across July, August, and September 2021. Solar irradiation, temperature, and humidity datasets were downloaded from Arpa Lombardia (www.arpalombardia.it accessed on 1 December 2021). 


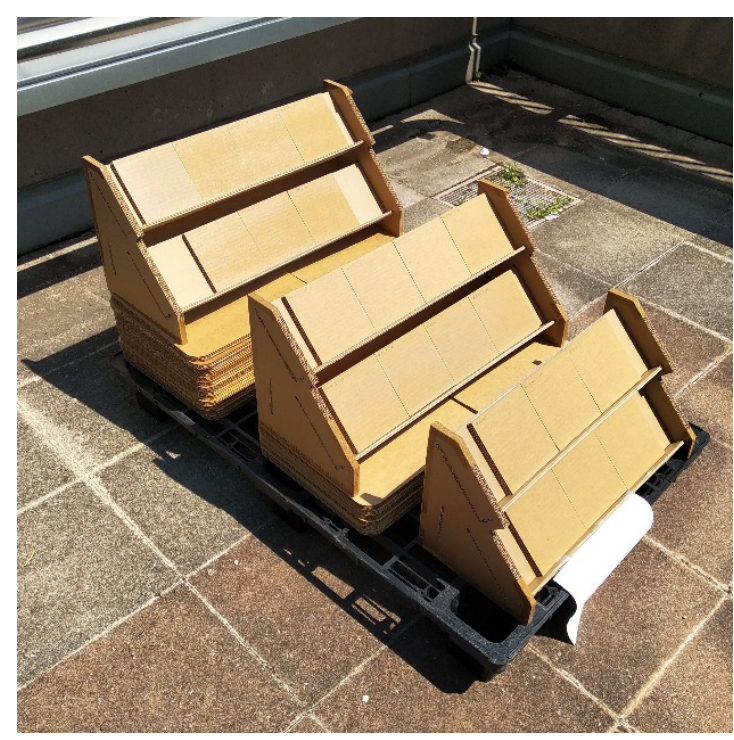

Figure 3. Samples on the racks exposed to natural UV-vis weathering.

Unless specified, UV-vis weathering time is 0 h, i.e., unweathered samples.

\subsection{Grammage}

The calculated grammage represents the average value of the deposit across the sample. Both wet and dry grammages were calculated. Additionally, solid content was also determined.

$$
\text { Wet Grammage }=g_{\text {wet }}=\frac{m_{1}-m_{0}}{A}
$$

where $A$ is the area of the sample, i.e., $0.0225 \mathrm{~m}^{2}$, while $m_{0}$ and $m_{1}$ are the mass of the sample before and right after spraying, respectively.

$$
\text { Dry Grammage }=g_{d r y}=g_{w e t} S_{c}
$$

where $S_{c}$ is the solid content, calculated as:

$$
S_{c}=\frac{m_{\text {dry }}-m_{\text {tare }}}{m_{\text {wet_coat }}} 100 \%
$$

where $m_{\text {wet_coat }}$ is the mass (in grams) of a pre-determined amount of the coating to be dried inside a petri dish placed in an over at $80{ }^{\circ} \mathrm{C}$ for at least $48 \mathrm{~h}, m_{d r y}$ is the mass (in grams) of the Petri dish once dried, and $m_{\text {tare }}$ is the mass of the empty Petri dish. $S_{c}$ measurements were done in triplicate.

\subsection{Water Absorption (Cobb Test)}

The Cobb test determines the amount of water absorbed by a cellulose-based substrate in a specified time. Water absorption (in $\mathrm{g} / \mathrm{m}^{2}$ ) was calculated through the Cobb1800 test according to Equation (4):

$$
W_{a}=\frac{m_{c 1}-m_{c 0}}{A_{C o b b}}
$$

where $m_{c 0}$ is the mass (in grams) of the sample before the Cobb test and $m_{c 1}$ is the mass (in grams) right after the Cobb test, while $A_{\mathrm{Cobb}}$ is the area of the test area (in $\mathrm{m}^{2}$ ) of the apparatus.

Specifically, all the coatings were tested before weathering $(t=0 h)$, at $100 \mathrm{~h}$, at $200 \mathrm{~h}$, and at $300 \mathrm{~h}$ of UV-vis radiation. 


\subsection{Contact Angle}

The sessile drop contact angle was measured using a 12 MP Sony IMX 486 sensor (pixel dimension: $1.25 \mu \mathrm{m}$ ) (Sony, Minato, Tokyo, Japan) with an f/2.2 lens. Apexel 20× macro lenses (Apexel, Shenzhen, Guangdong, China) were mounted onto the camera, fixing the focus at $3 \mathrm{~cm}$ from the macro lens and digitally zooming by $5.0 \times$. A micro-syringe applied de-ionised water drops onto the (un)coated substrate.

For each sample, five images were collected and analysed with ImageJ v1.53e, using the "Contact angle" plugin developed by Marco Brugnara [25]. The contact angle was determined by manual point procedure, i.e., by determining the baseline and selecting at least 10 points on the droplet contour.

\subsection{Fourier-Transform Infrared (FTIR) Spectroscopy}

FTIR measurements were carried out with a Nicolet Nexus FTIR spectrometer (Thermo Fisher Scientific, Waltham, MA, USA) coupled with a Thermo-Nicolet Continu $\mu$ m (Thermo Fisher Scientific, Waltham, MA, USA) infrared microscope and a liquid nitrogen cooled MCT detector (Thermo Fisher Scientific, Waltham, MA, USA). The micro-IR spectra were collected in transmission mode by depositing the samples on a diamond anvil cell (DAC). The adopted operational parameters for each recorded IR spectrum were $4 \mathrm{~cm}^{-1}$ resolution and 16 scans.

Both the mineral-filled coatings, i.e., T-POL and K-POL, were analysed. Refer to the supplementary material for the spectra.

\subsection{Scanning Electron Microscopy (SEM) + Energy Dispersive Spectrometry (EDS)}

Coated samples were analysed through SEM micrographs for each condition at 0 , 100, 200, and $300 \mathrm{~h}$ weathering time using a ZEISS EVO 50 (Zeiss, Wetzlar, Germany) electron microscope. $100 \times, 250 \times$, and $500 \times$ magnification were used to retrieve surface morphology, while magnifications ranging between 1000-5000 $\times$ were used to evaluate the film thickness (the images were analysed using ImageJ v1.53e).

A BRUKER QUANTAX 200 (Bruker, Billerica, MA, USA) analyser performed an EDS analysis to determine the filler nature in T-POL and K-POL, as well as the SG distribution.

\subsection{Spectrophotometry}

A portable Konica Minolta CM-2500d (Konica Minolta, Chiyoda, Tokyo, Japan) spectrophotometer with $\mathrm{D} 65 / 10^{\circ}$ colour space was used to retrieve the CIE $\mathrm{L}^{*} \mathrm{a}^{*} \mathrm{~b}^{*}$ colour coordinates of the samples to evaluate the possible colour changes due to UV-vis weathering. Focusing on the user visual perception, Specular Component Excluded (SCE) data were retrieved [26].

CIE $\mathrm{L}^{*} \mathrm{a}^{*} \mathrm{~b}^{*}$ coordinates resulted from an average of nine measurements for each sample. Following, $\Delta \mathrm{E}^{*}$ (CIEDE2000) colour difference against the unweathered control sample $(\mathrm{U})$ was determined using the following equation:

$$
\Delta E^{*}=\sqrt{\left(\frac{\Delta L^{\prime}}{k_{L} S_{L}}\right)^{2}+\left(\frac{\Delta C^{\prime}}{k_{C} S_{C}}\right)^{2}+\left(\frac{\Delta H^{\prime}}{k_{H} S_{H}}\right)^{2}+R_{T}\left(\frac{\Delta C^{\prime}}{k_{C} S_{C}}\right)\left(\frac{\Delta H^{\prime}}{k_{H} S_{H}}\right)}
$$

All the parameters inside Equation (5) were defined and discussed elsewhere [27]. In particular, $\Delta L^{\prime}$ is the lightness difference, whereas $\Delta C^{\prime}$ and $\Delta H^{\prime}$ are the modified chroma and hue polar coordinates difference, respectively; instead, $k_{L}, k_{C}$, and $k_{H}$ are constants (all set equal to 1), whereas $S_{L}, S_{C}$, and $S_{H}$ are the compensations to the perceptual uniformity issue.

\subsection{Stool Preparation}

Two corrugated cardboard stools (height $=0.58 \mathrm{~m}$; diameter $=0.35 \mathrm{~m}$; weight $=6.5 \mathrm{~kg}$ ) were spray-coated and exposed to urban environment conditions. The stools were composed of several cardboard layers glued together, plus a forex disk for sitting placed on the top. 
Coating occurred with the same methodology as for the samples. The stools (Figure 4) were treated by splitting the surface into halves and allocating one for each condition (UC, T-POL, K-POL and SG). Drying conditions depended on the water absorption and contact angle performance. Subsequently, UC, K-POL_A, T-POL_H, and SG_A were applied.

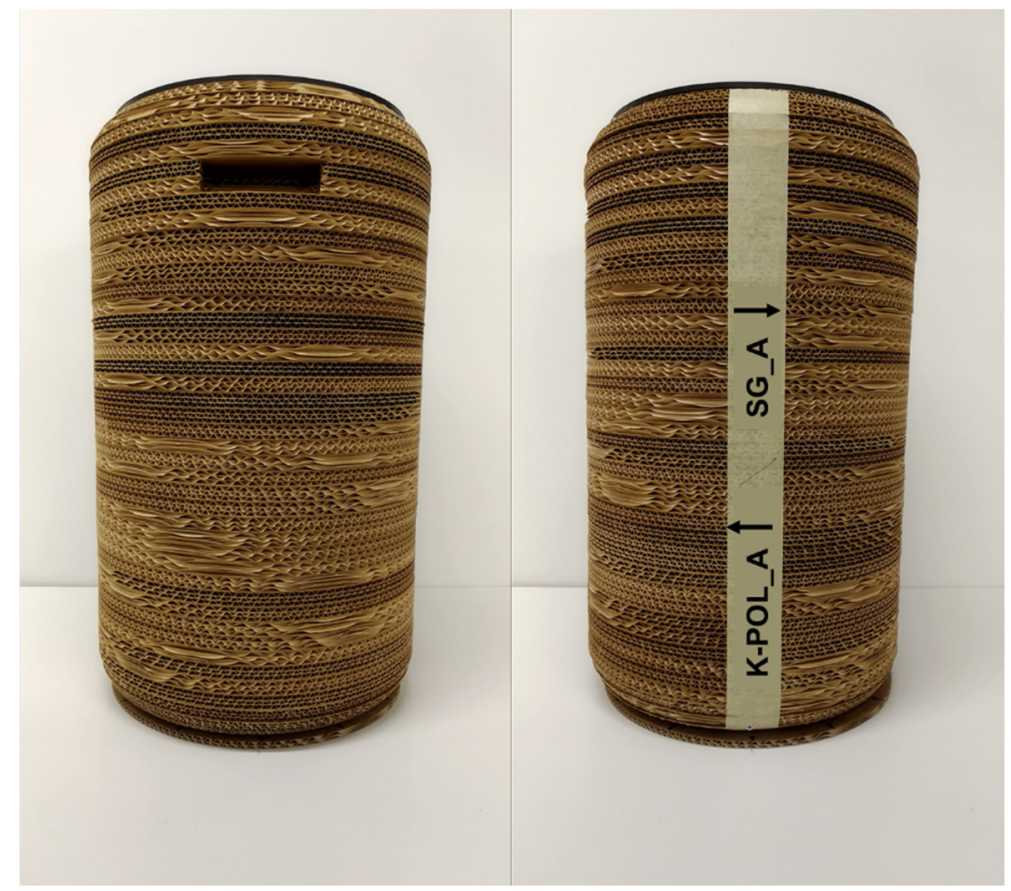

Figure 4. Coated stools. T-POL, K-POL, and SG were spray-coated on one half each, plus one uncoated (UC) half.

The stools underwent natural weathering on a balcony in Bovisa (Milan, Italy) (Figure 5) and were facing northwest. The balcony overlooked a busy road and was covered (above) by another balcony, while a metallic grid parapet protected the sides. The temperature and humidity were downloaded from Arpa Lombardia.

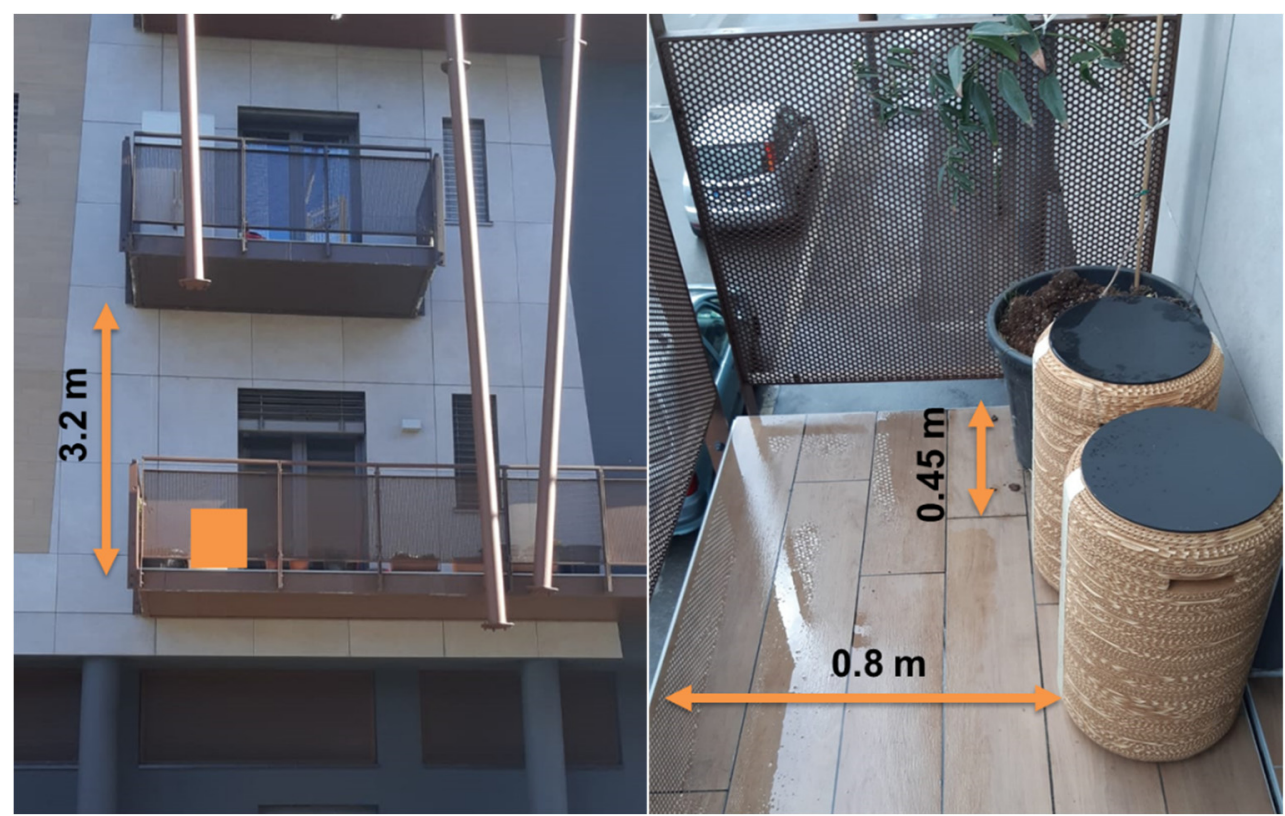

Figure 5. Balcony in Bovisa (Milan, Italy) where the stools were exposed. 
Sprinkles from rain hitting the balcony parapet, as well as direct rain (if raining sideways), impacted the stools. Qualitative changes were monitored and recorded through pictures over five months, i.e., from June to October 2021 (included).

\section{Results}

Spray-coating technology proved to coat both the substrates and the stools, though TPOL and K-POL are commercial grades meant for rod, blade, flexo, and similar technologies. The results showed variable coating grammage (as reported in Table 1)-i.e., the thicknessthat, since we used the same processing parameters across different coating products, depend on variable solid content.

Table 1. Solid content and grammage of the coating products considered in this work.

\begin{tabular}{ccc}
\hline Coating & Solid Content [\%] & Dry Grammage $\left[\mathbf{g} / \mathbf{m}^{\mathbf{2}}\right]$ \\
\hline T-POL & $60 \%$ & $49 \pm 9$ \\
K-POL & $49 \%$ & $20 \pm 2$ \\
SG & $2.8 \%$ & $1.2 \pm 0.3$ \\
\hline
\end{tabular}

\subsection{Cobb Test}

Figure 6 reports the average Cobb values obtained in this work for all the investigation matrix conditions. Considering the unweathered samples, K-POL-coated samples drastically reduced the water absorption (around $-90 \%$ ) in both drying conditions compared to the UC samples, whereas SG only slightly improved the water barrier behaviour (almost $-15 \%)$. On the contrary, T-POL showed, depending on the drying conditions, opposite water barrier properties. Given this, the room drying conditions did not improve the properties, whereas oven drying conditions provided a reduction of almost $-95 \%$.

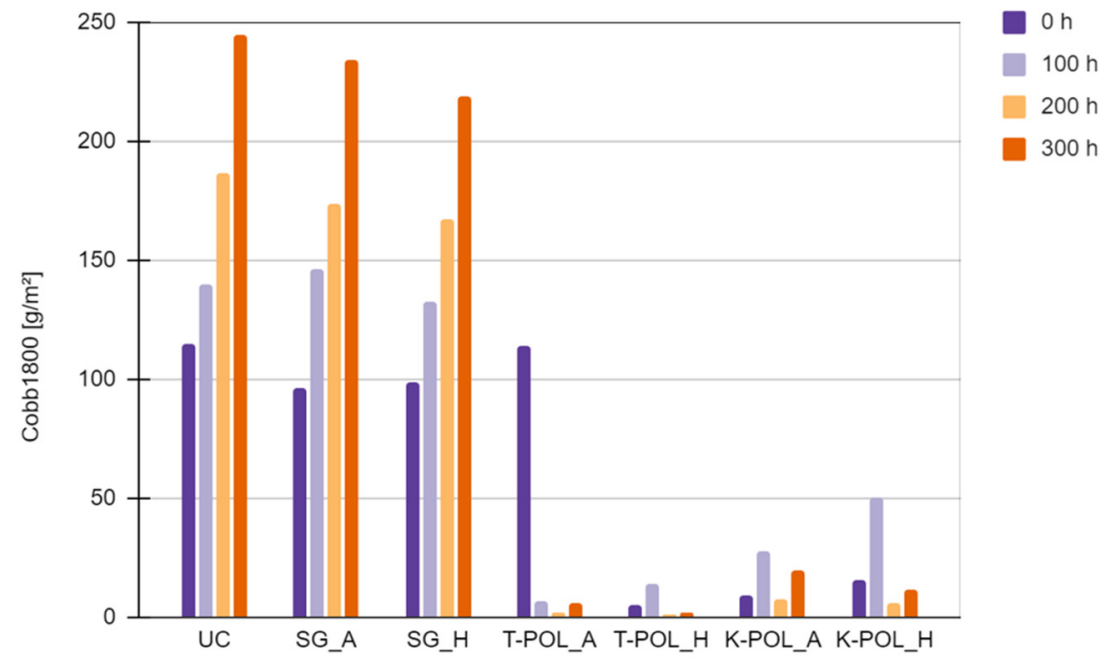

Figure 6. Water absorptiveness (Cobb test) for all the coatings, for both weathered $(100 \mathrm{~h}, 200 \mathrm{~h}$, and $300 \mathrm{~h})$ and unweathered $(0 \mathrm{~h})$ samples.

The results are consistent with similar works published in the literature [15,28], with water absorption generally lower than $50 \mathrm{~g} / \mathrm{m}^{2}$. In particular, previous works showed how polymers and mineral fillers [15] can reduce the Cobb values up to less than $10 \mathrm{~g} / \mathrm{m}^{2}$, as it is for T-POL_H.

Considering, the water barrier stability over time, Figure 6 clearly shows how UC samples worsened their water barrier properties due to weathering by more than doubling the original values. Therefore, in order to use corrugated cardboard in durable products, performance stability is of major concern. K-POL samples retained good performance in the considered period $(0-300 \mathrm{~h}$ ), being generally well below the Cobb values for unweathered UC. Unsurprisingly, the SG-coated samples followed the same trend as the UC ones, 
suggesting a possible inability of the coating to prevent water from reaching the substrate. T-POL, instead, achieved the best results for the oven-dried weathered samples (up to $-98 \%$ compared to unweathered UC samples). Such behaviour suggests the presence of UV-setting polymers/additives in T-POL that produce a similar performance as the thermal coat set.

The Cobb values also changed for dry-coating grammage, reducing as the coating grammage increased-as shown in Figure 7 (unweathered samples) and as reported in other works $[15,28]$.

Unweathered samples, Cobb1800

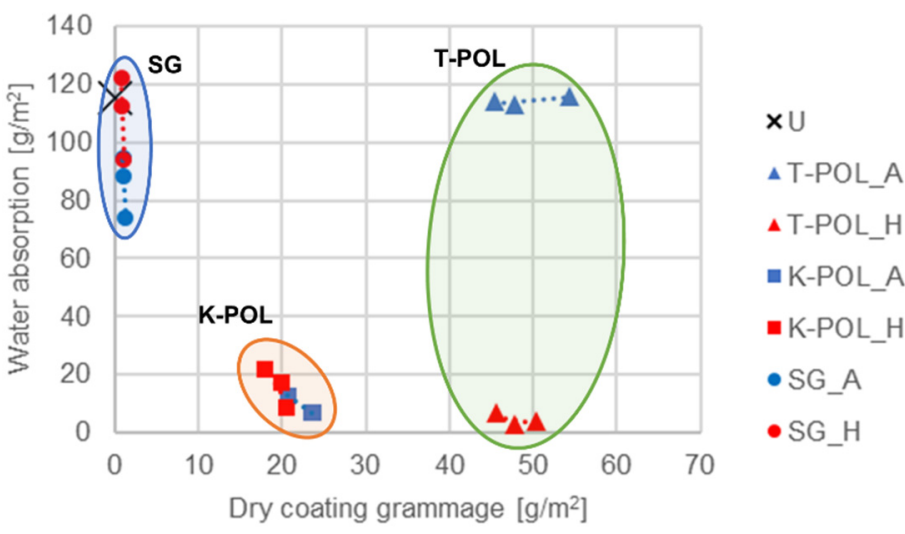

Figure 7. Water absorptiveness for the UC, T-POL, K-POL and SG unweathered samples.

Moreover, we investigated the effects of drying time for T-POL (0-, 5-, 10-, 30-, and 60-min drying time), observing how even 5 min of drying strongly impacts the water absorption (almost $-60 \%$ compared to T-POL_A).

\subsection{SEM and EDS Analysis}

Weathering resistance is crucial for durable items like CCF. Indeed, the outdoor environment implies solar radiation, and thermal and humidity cycles. During UV-vis weathering, the average global solar radiation was $650 \mathrm{~W} / \mathrm{m}^{2}$, whereas the average temperature was $27 \pm 3{ }^{\circ} \mathrm{C}$ (ranging 19.5-32.7 ${ }^{\circ} \mathrm{C}$ ) and the average relative humidity was $47 \% \pm 10 \%$ (ranging $15.4 \%-70.4 \%$ ).

Lignin chromophores for UV photodegradation can explain the worsening of the Cobb values in SG and UC; furthermore, lignin is hydrophobic, compared to cellulose and hemicellulose components of wood fibres [29]. Additionally, temperature and relative humidity may have played an important role in degrading cellulose [30,31] and the SG coating, further worsening the properties of the substrate. The latter is more relevant for thinner and inhomogeneous coatings compared to thicker and homogeneous ones. SEM analysis provided information about the coating thickness (Table 2) and morphology.

Table 2. Ranges for coating thickness.

\begin{tabular}{cc}
\hline Coating & Thickness $[\mu \mathrm{m}]$ \\
\hline T-POL & $25-40$ \\
K-POL & $10-16$ \\
SG & $\sim 1$ \\
\hline
\end{tabular}

Several surface drop-like defects stood out on the T-POL surface; the average diameter was $33 \pm 17 \mu \mathrm{m}$ with some flaws reaching a dimension of around $100 \mu \mathrm{m}$. Such morphology led to perceiving a rough and buttered coating surface by the naked eye. These defects were attributed to the material viscosity due to the presence of the coarse filler (as visible in Figure 8a) [32]. Consequently, the spraying parameters might not allow for a high Weber number, leading to low atomization [33]. Moreover, according to [34], in-flight evaporation 
may be an additional cause of the irregularities. T-POL EDS analysis provided peaks for the plate-like micro-sized minerals that were confirmed to be associated with the talc.

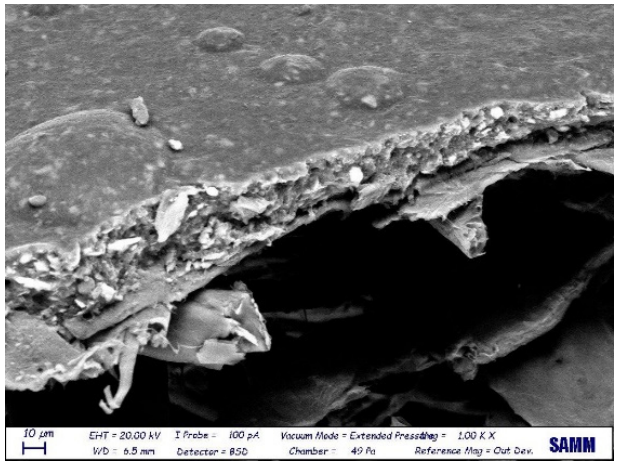

(a)

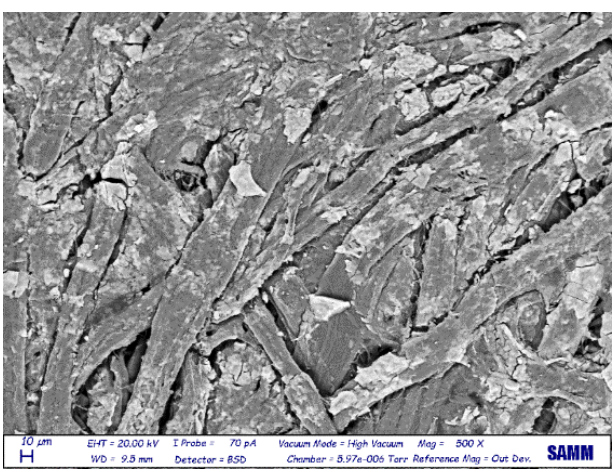

(c)

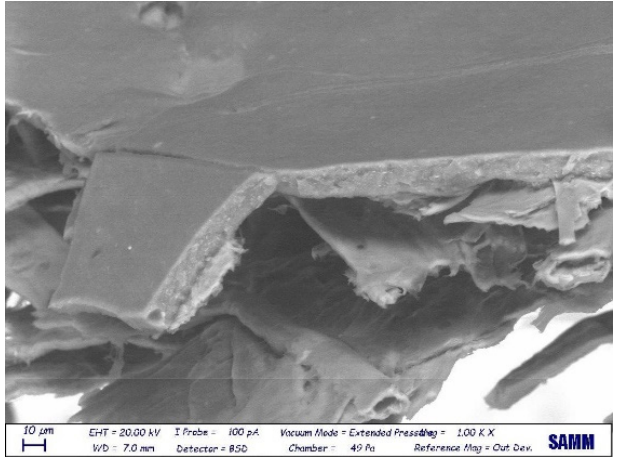

(b)

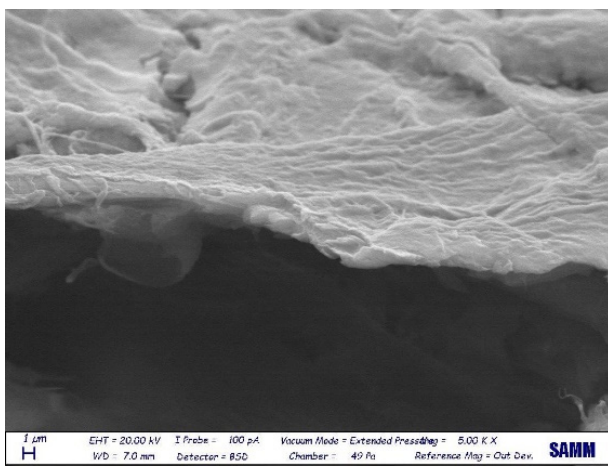

(d)

Figure 8. Surface micrographs for the coated samples. (a) Plate-like filler (cross-section) and drop-like defects in T-POL_H coating $(\mathrm{M}=1000 \times)$; (b) Cross-section of the K-POL_A coating $(\mathrm{M}=1000 \times)$; (c) SG_A SEM surface micrograph $(\mathrm{M}=500 \times)$; (d) Cross-section of the unweathered SG_A coating $(M=5000 \times)$.

K-POL, instead, features a smoother surface (Figure $8 \mathrm{~b}$ ) and has pinholes rather than drop-like defects. The average pinhole dimension was $27 \pm 7 \mu \mathrm{m}$. Al and Si peaks in the K-POL EDS analysis were instead attributed to kaolin (at finer dimensions compared to TPOL), confirming the FTIR analysis. The authors do not exclude further functional additives that may improve adhesion to cellulose fibres, barrier properties, compatibilization, etc. for both K-POL and T-POL $[6,35]$.

The low SG solid content led to a surface that kept the underlying fibres visible (Figure 8c), i.e., achieving thinner coatings than K-POL and T-POL. Taking a closer look, a uniformly spread coating (Figure $8 \mathrm{~d}$ ) and solid, irregularly spread agglomerations (Figure 8c) are visible across the surface. Moreover, SG agglomerates featured several cracks because of internal stresses during solvent evaporation [36]. SG EDS mapping provided, despite the agglomerates, that fluorine distribution was even across the surface, while the agglomerates were mainly composed of silica.

The defects and inhomogeneities in the coating influence the overall macroscopic properties, hence the performance, which is something to be avoided in packaging applications since the environmental impact of content loss is high, especially for food products [37]. In this specific work, where no such performance is needed, defects may be tolerated, given the coverage of the substrate.

\subsection{Contact Angle (CA)}

Generally, the CA values of the coated samples showed slight variations over weathering time compared to the UC samples (Figure 9); indeed, in the latter case, CA dropped 
by $-48 \%$ after $300 \mathrm{~h}$. Such behaviour is a consequence of lignin photodegradation due to UV-vis radiation, as is widely reported in the literature [38,39]. On the contrary, all the coated samples showed unaltered wettability both upon weathering and as a function of drying conditions. The behaviour can therefore be associated with surface chemistry and is independent of the coating thickness, which was instead particularly relevant in absorption tests.

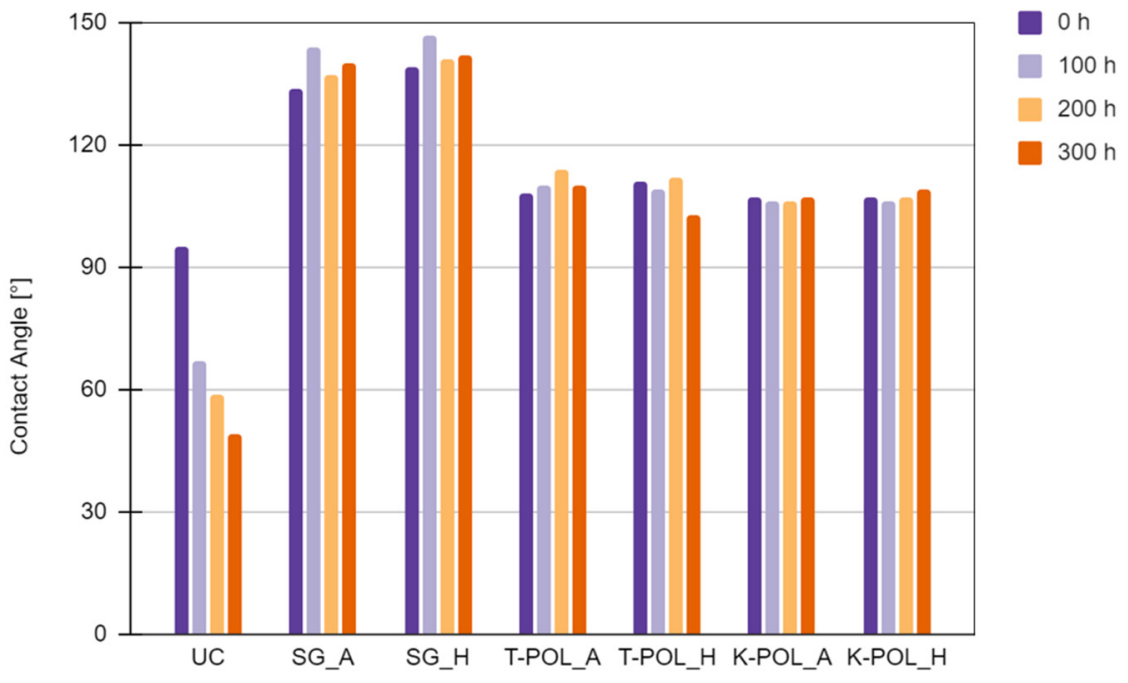

Figure 9. Contact angle values for the unweathered and weathered samples.

SG showed contact angles ranging between $135-147^{\circ}$, thus it is close to being superhydrophobic $\left(\mathrm{CA} \geq 150^{\circ}\right)$ - as was achieved in similar works [23,40]. Furthermore, previous works [7] reported how fluorine-containing coatings provide one of the lowest free-surface energies. Instead, regarding the T-POL and K-POL coatings, their contact angle ranged between $104-114^{\circ}$, which is consistent with other polymeric coatings $[16,18]$. Although SG provides lower wettability, hence the water droplets easily slip off the substrate, the CA values generally did not show a correlation with Cobb test performance (excluding UC samples). This is likely related to the coating thickness, since the limited surface coverage offered by SG is sufficient to modify the surface contact angle, although it cannot hinder water absorption as it does not offer a sufficient barrier effect.

\subsection{Spectrophotometry}

Spectrophotometry analyses demonstrated an influence of coating treatment on the substrate colour only for T-POL-coated samples, with a $\Delta \mathrm{E}^{*}$ higher than 3 in one case, and in the other cases, the values, which were lower than 1.5, indicate variations that are not appreciable by the human eye. Concerning the weathering, the data showed how $\Delta \mathrm{E}^{*}$ peaked within the $100-200 \mathrm{~h}$ weathering time range (Figure 10). Generally, all the samples showed an important colour variation at the beginning of weathering, then maintained similar $\Delta \mathrm{E}^{*}$ values from $100 \mathrm{~h}$ to $200 \mathrm{~h}$; after such times, a decrease occurred for all the samples except for K-POL, which maintained unaltered $\Delta \mathrm{E}^{*}$ values (Figure 10). However, visible urban environment dirt accumulated on the surface of the samples, possibly contributing to reducing the $\mathrm{L}^{*}$ coordinate. Such behaviour is similar to previous works [41], though $\Delta \mathrm{E}^{*}$ was calculated following the CIE76 formula instead of CIEDE2000.

Nevertheless, each sample showed a perceivable colour difference $\left(\Delta \mathrm{E}^{*}>2\right)$ for the weathered condition.

Referring to the specific $\mathrm{L}^{*}, \mathrm{a}^{*}$, and $\mathrm{b}^{*}$ coordinates, T-POL showed a strong initial $\mathrm{L}^{*}$ uptrend. $\mathrm{b}^{*}$ is correlated to the yellowing phenomenon (i.e., an increase in $\mathrm{b}^{*}$ values represent yellower surfaces), which is widely reported for wood fibres and mainly attributed to lignin photodegradation $[29,39,42]$. It is particularly evident for T-POL, compared to 
UC, SG, and K-POL, how the yellowing effect is retarded (Figure 10), i.e., protecting the substrate against UV degradation.
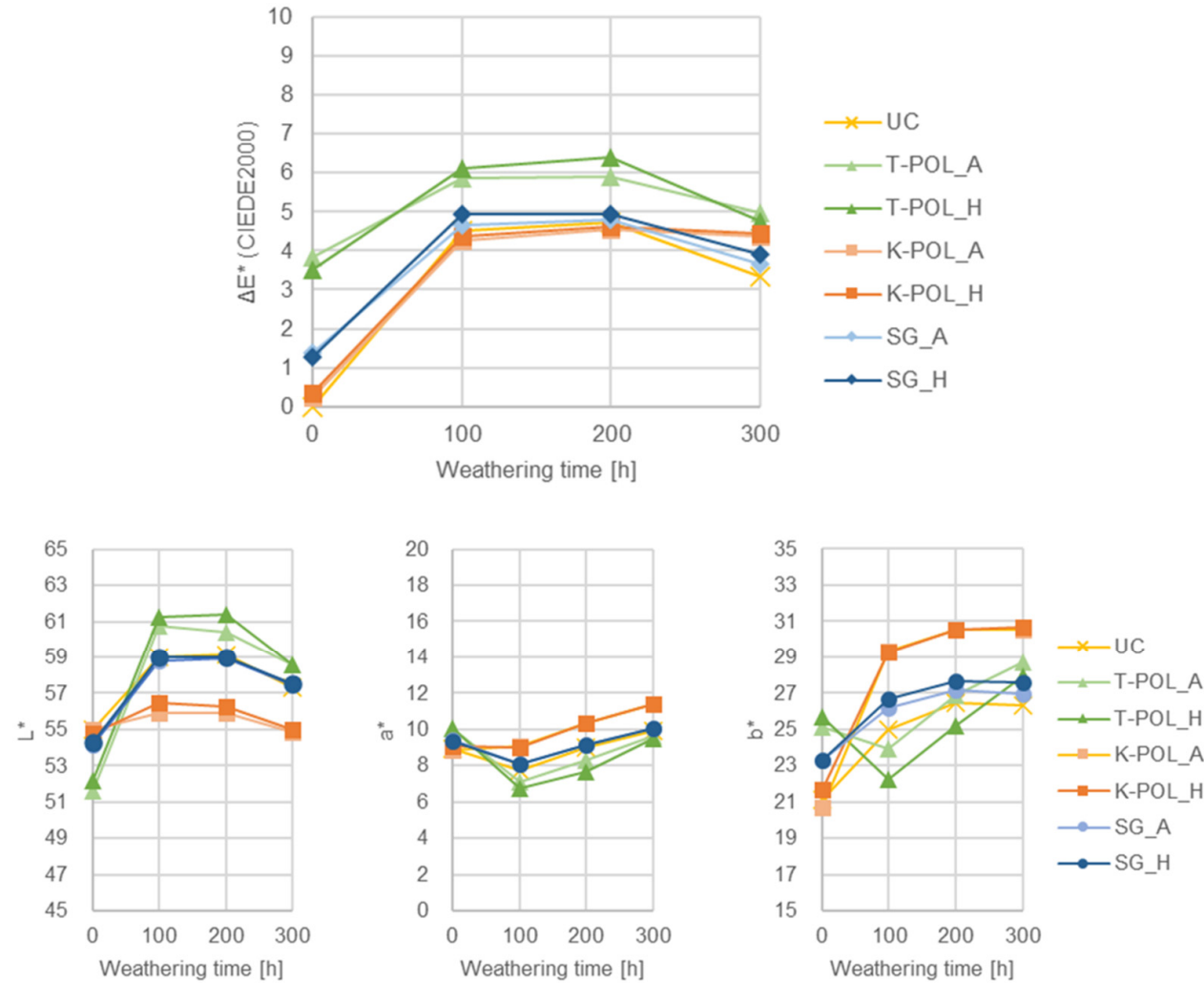

Figure 10. (Above) $\Delta E^{*}$ (CIEDE2000) progression for the different samples. (Below) $\mathrm{L}^{*}$, $\mathrm{a}^{*}$, and $\mathrm{b}^{*}$ coordinates evolution in time.

Both in Figures 10 and 11 it can be observed how SG-coated samples follow the behaviour of the UC samples, indicating that the protection against UV irradiation is negligible. Indeed, the thin coating layer is not able to macroscopically influence the user aesthetic perception nor the UV degradation of the substrate. K-POL, on the other side, showed larger $\Delta \mathrm{b}^{*}$ than $\mathrm{UC}$, suggesting that the coating itself yellowed and contributed to the overall perceptual colour change.
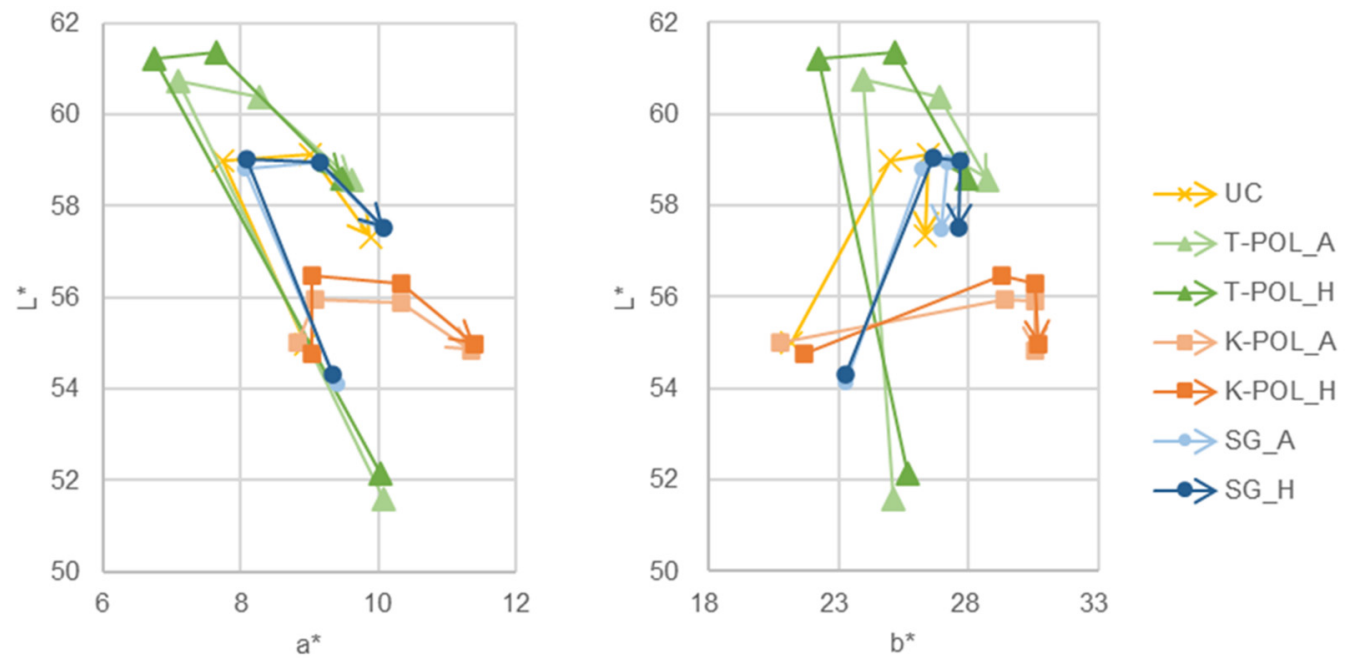

Figure 11. (Left) $L^{*}$ vs. $a^{*}$ coordinates evolution for all the samples; (Right) $L^{*}$ vs. $b^{*}$ coordinates evolution for all the samples. Arrows indicate increasing time in measurements recording. 
Finally, the drop in the lightness alongside negligible $\mathrm{a}^{*}$ and $\mathrm{b}^{*}$ variations after $200 \mathrm{~h}$ weathering time may have driven the drop in the $\Delta \mathrm{E}^{*}$ values.

\subsection{Product Exposure to the Urban Environment}

The products underwent temperature and humidity changes. The average temperature was $24 \pm 4{ }^{\circ} \mathrm{C}$ (ranging $12-36^{\circ} \mathrm{C}$ ), while the average humidity was $55 \pm 15 \%$ (ranging 15-99\%). No changes occurred upon initial observation after one month of exposure, except 2-3 mm of layer detachment (as visible in Figure 12) whose occurrence should not be related to the swelling of the applied coating since, in this work, the finished stool was spray-coated (hence, no coating was present in between the CCF layers). Instead, it should be related to the glueing system that holds together the product layers and the natural tendency of the corrugated cardboard sheet to bend due to the moisture absorption-desorption cycles.

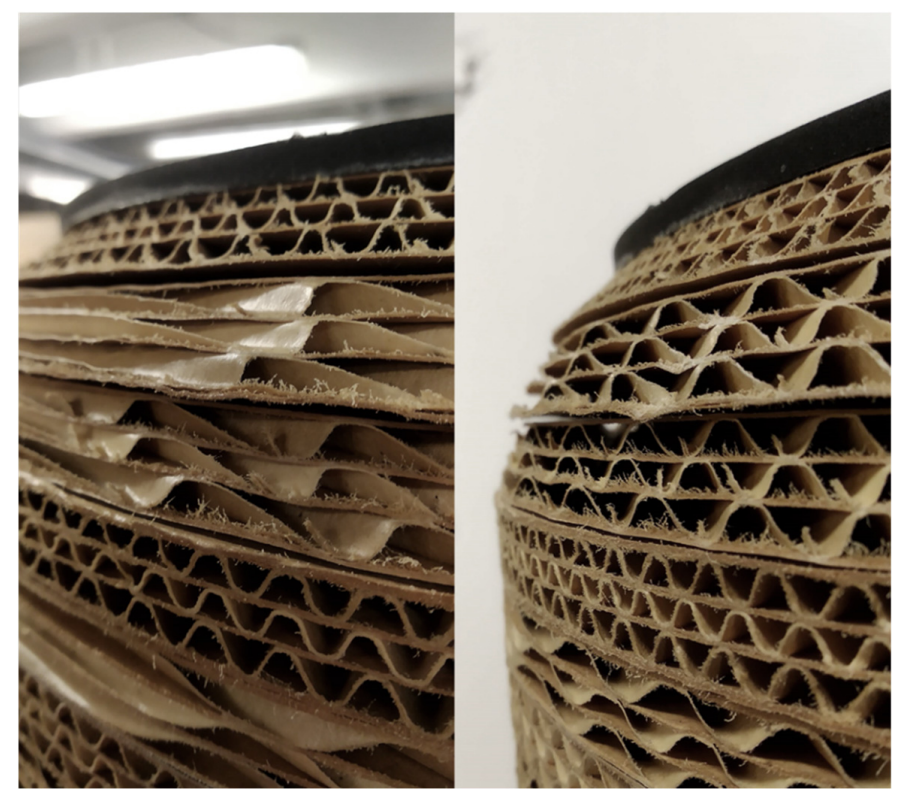

Figure 12. Top-layers detachment of the stools ( $0-1$ month exposure time).

In the second month, the layer detachment settled at 3-4 mm. Additionally, water activity wrinkled only the liners of the UC half, as shown in Figure 13. Indeed, since the other coatings remained intact, it is suggested that the coatings protected the layers. The SG coating half-wrinkled during the third month, highlighting that hydrophobicity helps to reduce the amount of water that wets the substrate. The following months (late autumn/winter) will provide further relevant data in determining the resistance of the stools to cold and humid/foggy weather, which characterises northern Italy.

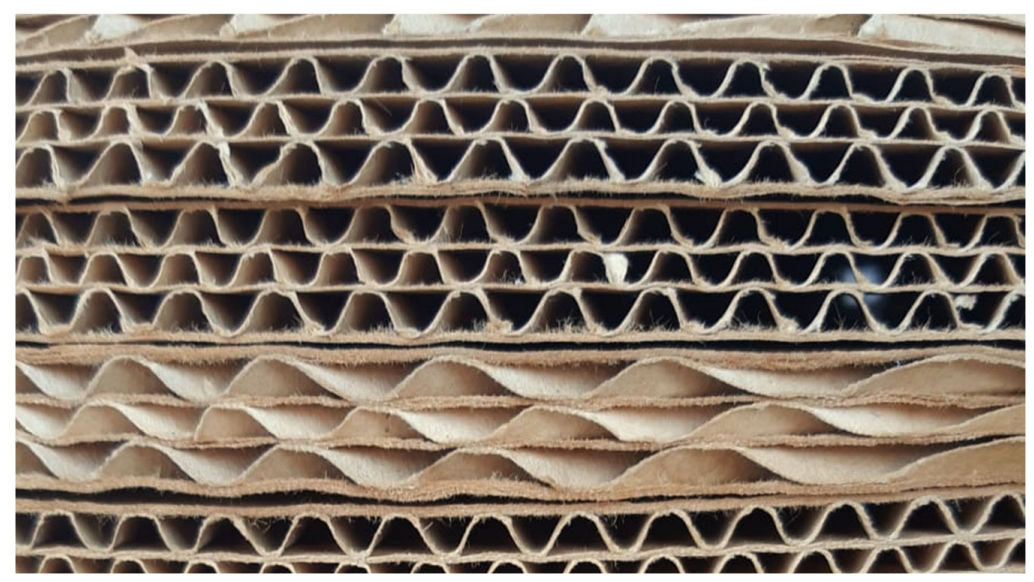

Figure 13. Liner wrinkling on the UC half of the stool (due to the effect of water sprinkles). 


\section{Discussion}

The contact angles of the coated samples increased compared to the uncoated ones by up to $150^{\circ}$ (for SG), i.e., near superhydrophobic. However, no correlation between the contact angle and absorption values was observed. Moreover, SG provided the worst Cobb1800 values compared to T-POL and K-POL. This was related to the thin and widely cracked coating surface, hindering the barrier effect provided by the other coatings. Natural weathering-UV, humidity, and temperature-significantly changed the Cobb values but not the CA (except for the UC samples) due to substrate photodegradation and coating flaws, increasing substrate water absorption, and confirming the relevance of the absorption tests with respect to the CA ones to state the performance of such coatings. Nevertheless, in the case of K-POL and T-POL, the Cobb values remained small, suggesting a potential use of coatings for pieces of furniture due to the restricted water absorption even after prolonged weathering. Previous literature showed for unweathered and non-commercially available grades, that coatings can improve water barrier properties of corrugated cardboard; however, it was not possible to compare the results related to weathering evolution. Indeed, prolonged weathering times showed a performance change for both UC and SG, which was significant for applications where durability is key.

Furthermore, the natural weathering affected the aesthetic properties of the samples, causing a perceivable colour change. The yellowing effect proceeded until 200-300 h, where the $b^{*}$ coordinate reached a plateau (except for T-POL).

Although oven-dried T-POL provided the best results, coat grammages are more than double of K-POL and almost fifty times higher than SG, which is still higher than other works [43]. Therefore, considering that the use of T-POL implies higher environmental and economic costs (in terms of energy, equipment, and material, since the cost per kilogram is in the same order of magnitude) for a comparable water-absorption performance for cardboard furniture, K-POL may be preferred by looking at the Cobb test. Additionally, higher coating grammages mean a higher coating ratio, hence the possible higher coarse and fine rejects during the recycling process at a paper mill (to be evaluated with proper testing, such as UNI 11743:2019).

Nevertheless, the coating grammage differences could be reduced by optimising the spraying process for each coating grade. However, changing the spraying parameters affects the atomisation, in-flight evaporation, and drop impact behaviour [33].

A better maintaining of surface aesthetics, together with better resistance to disintegration, is undoubtedly the result a good coating should present. The considered coating grades showed good properties, although it requires the optimisation of the spraying deposition process to reduce surface defects and obtain the best performance.

\section{Conclusions}

Corrugated cardboard samples and stools were successfully coated via a facile spraycoating method, which is readily transferrable. Due to the technology and the manual processing, the coatings showed surface defects and varying thickness to some extent. Nevertheless, polymeric coatings, i.e., K-POL and T-POL, showed the best performance that perdured in time ( $-80-90 \%$ in water absorption compared to the uncoated samples); however, T-POL required heat or irradiation to set the coat. The perceived colour change may indicate UV deterioration, though not directly linked to water barrier properties. Finally, operational parameters are essential, as seen by the effect on the coating morphology, i.e., its performance.

Future works could consider additional UV-protecting coating to attenuate the colour difference between newer and older products, especially when single pieces of furniture substitution is involved, as well as address the effects on the recyclability process of such products. 
Supplementary Materials: The following are available online at https:/ / www.mdpi.com/article/ 10.3390 / coatings12010010/s1, Figure S1: FTIR analysis of T-POL and its constituents, Figure S2: FTIR analysis of K-POL and its constituents.

Author Contributions: Conceptualization, A.M. and B.D.C.; methodology, A.M. and M.V.D.; investigation, A.M., A.L.; data curation, A.M.; writing-original draft preparation, A.M. and M.V.D.; writing-review and editing, A.M. and M.V.D.; visualization, A.M., M.V.D. and A.L.; supervision, M.P.P. and B.D.C.; funding acquisition, M.P.P. and B.D.C. All authors have read and agreed to the published version of the manuscript.

Funding: The work was funded by Regione Lombardia, call Innodriver S3 2019, industrial partner Azienda Scatolificio Lariano Srl.

Data Availability Statement: Data available on request. The data presented in this study are available on request from the corresponding author. Most data are contained within the article.

Acknowledgments: The authors would like to thank Emeritus Alberto Cigada and Umberto Bellè for their suggestions.

Conflicts of Interest: The authors declare no conflict of interest.

\section{References}

1. Cepi. Key Statistics 2019—European Pulp \& Paper Industry. 2020. Available online: https:/ /www.cepi.org/wp-content/uploads / 2020/07 / Final-Key-Statistics-2019.pdf (accessed on 18 January 2021).

2. Bordenave, N.; Grelier, S.; Coma, V. Hydrophobization and antimicrobial activity of chitosan and paper-based packaging material. Biomacromolecules 2010, 11, 88-96. [CrossRef]

3. Cunha, A.G.; Gandini, A. Turning polysaccharides into hydrophobic materials: A critical review. Part 1. Cellulose. Cellul 2010, 17, 875-889. [CrossRef]

4. Farhat, W.; Venditti, R.A.; Hubbe, M.; Taha, M.; Becquart, F.; Ayoub, A. A Review of Water-Resistant Hemicellulose-Based Materials: Processing and Applications. ChemSusChem 2017, 10, 305-323. [CrossRef] [PubMed]

5. Hansen, N.M.L.; Plackett, D. Sustainable Films and Coatings from Hemicelluloses: A Review. Biomacromolecules 2008, 9, $1493-1505$. [CrossRef] [PubMed]

6. Piergiovanni, L.; Limbo, S. Food Packaging-Materiali, Tecnologie e Qualità Degli Alimenti, 1st ed.; Springer: Milano, Italy, 2010.

7. Samyn, P. Wetting and hydrophobic modification of cellulose surfaces for paper applications. J. Mater. Sci. 2013, 48, 6455-6498. [CrossRef]

8. Nair, A.; Kansal, D.; Khan, A.; Rabnawaz, M. Oil- and water-resistant paper substrate using blends of chitosan-graftpolydimethylsiloxane and poly(vinyl alcohol). J. Appl. Polym. Sci. 2021, 138, 50494. [CrossRef]

9. Nair, A.; Kansal, D.; Khan, A.; Rabnawaz, M. New alternatives to single-use plastics: Starch and chitosan-graft-polydimethylsiloxanecoated paper for water- and oil-resistant applications. Nano Sel. 2021. [CrossRef]

10. Lavoine, N.; Bras, J.; Desloges, I. Mechanical and barrier properties of cardboard and 3D packaging coated with microfibrillated cellulose. J. Appl. Polym. Sci. 2014, 131, 40106. [CrossRef]

11. Fowle, J.; Kirwan, M.J. Paper-based flexible packaging. In Handbook of Paper and Paperboard Packaging Technology, 2nd ed.; Kirwan, M.J., Ed.; Wiley-Blackwell: Hoboken, NJ, USA, 2013; pp. 91-124.

12. Sangl, R.; Werner, A.; Kogler, W.; Tietz, M. Surface Sizing and Coating. In Handbook of Paper and Board, 2nd ed.; Holik, H., Ed.; Wiley-VCH Verlag GmbH \& Co. KGaA: Weinheim, Germany, 2013; pp. 745-784.

13. Hartono, N.; Christiani, A.; Larasati, C.K. Modular Furniture Made From Corrugated Box Waste Using Design for Environment Guidelines. J. Environ. Sci. Sustain. Dev. 2019, 2, 48-60. [CrossRef]

14. Jaramillo, H.; Gallardo, R.; Martinez, C. Street furniture in recycled and resignified materials. J. Phys. Conf. Ser. 2018, 1126, 012066. [CrossRef]

15. Popil, R.E. Optimizing water resistance of linerboard coatings using pigments. Tappi J. 2006, 5, 18-26.

16. Dong, L.; Hu, H.; Cheng, F.; Yang, S. The water resistance of corrugated paper improved by lipophilic extractives and lignin in APMP effluent. J. Wood Sci. 2015, 61, 412-429. [CrossRef]

17. Salsman, K. Waterborne polyester resins in repulpable paper coatings. Pap. Age. 1998, 114, 18-19.

18. Cataldi, P.; Profaizer, M.; Bayer, I.S. Preventing Water-Induced Mechanical Deterioration of Cardboard by a Sequential Polymer Treatment. Ind. Eng. Chem. Res. 2019, 58, 6456-6465. [CrossRef]

19. Gaikwad, K.K.; Singh, S.; Lee, Y.S. Functional Corrugated Board with Organic and Inorganic Materials in Food Packaging Applications: A Review. Korean J. Packag. Sci. Technol. 2016, 22, 49-58. [CrossRef]

20. Paul, U.C.; Heredia-Guerrero, J.A. Paper and Cardboard Reinforcement by Impregnation with Environmentally Friendly HighPerformance Polymers for Food Packaging Applications. Sustain. Food Packag. Technol. 2021, 281-304. [CrossRef]

21. Cepi. Paper-Based Packaging Recyclability Guidelines [Internet]. 2019. Available online: http://www.cepi.org/system/files/ publications/19-3038_Recyclability_A4_EN_20200107.pdf (accessed on 8 November 2020). 
22. CONAI. Linee Guida per la Facilitazione delle Attività di Riciclo Degli Imballaggi a Prevalenza Cellulosica [Internet]. 2020. Available online: http:/ / www.progettarericiclo.com/docs/linee-guida-la-facilitazione-delle-attivita-di-riciclo-degli-imballaggiprevalenza-cellulosica (accessed on 21 August 2020).

23. Ogihara, H.; Xie, J.; Okagaki, J.; Saji, T. Simple method for preparing superhydrophobic paper: Spray-deposited hydrophobic silica nanoparticle coatings exhibit high water-repellency and transparency. Langmuir 2012, 28, 4605-4608. [CrossRef] [PubMed]

24. Zhang, S.; Li, W.; Wang, W.; Wang, S.; Qin, C. Reactive superhydrophobic paper from one-step spray-coating of cellulose-based derivative. Appl. Surf. Sci. 2019, 497, 143816. [CrossRef]

25. Brugnara, M. Contact Angle plugin [Internet]. 2006. Available online: https://imagej.nih.gov/ij/plugins/contact-angle.html (accessed on 5 March 2021).

26. Konica Minolta. Understanding Specular Component Included (SCI) and Specular Component Excluded (SCE) [Internet]. 2019. Available online: https://sensing.konicaminolta.asia/specular-component-included-sci-vs-specular-component-excluded-sce/ (accessed on 22 May 2021).

27. Sharma, G.; Wu, W.; Dalal, E.N. The CIEDE2000 color-difference formula: Implementation notes, supplementary test data, and mathematical observations. Color Res. Appl. 2005, 30, 21-30. [CrossRef]

28. Ford, E.; Popil, R.E.; Kumar, S. Breathable Water-Resistant Linerboard Coatings by Electrospraying Application. BioResources 2009, 4, 714-729.

29. Patel, J.P.; Parsania, P.H. Characterization, testing, and reinforcing materials of biodegradable composites. In Biodegradable and Biocompatible Polymer Composites: Processing, Properties and Applications; Elsevier Ltd.: Amsterdam, The Netherlands, 2018 ; pp. 55-79.

30. Barański, A.; Dutka, D.; Dziembaj, R.; Konieczna-Molenda, A.; Łagan, J.M. Effect of Relative Humidity on the Degradation Rate of Cellulose. Methodol. Stud. 2004, 25, 68-74.

31. Małachowska, E.; Pawcenis, D.; Dańczak, J.; Paczkowska, J.; Przybysz, K. Paper Ageing: The Effect of Paper Chemical Composition on Hydrolysis and Oxidation. Polymers 2021, 13, 1029. [CrossRef]

32. Rueda, M.M.; Auscher, M.C.; Fulchiron, R.; Périé, T.; Martin, G.; Sonntag, P. Rheology and applications of highly filled polymers: A review of current understanding. Prog. Polym. Sci. 2017, 66, 22-53. [CrossRef]

33. Reale, A.; La Notte, L.; Salamandra, L.; Polino, G.; Susanna, G.; Brown, T.M.; Brunetti, F.; Di Carlo, A. Spray Coating for Polymer Solar Cells: An Up-to-Date Overview. Energy Technol. 2015, 3, 385-406. [CrossRef]

34. Eslamian, M. A Mathematical Model for the Design and Fabrication of Polymer Solar Cells by Spray Coating. Dry. Technol. 2013, 31, 405-413. [CrossRef]

35. Tavakolian, S.; Ahari, H.; Givianrad, M.H.; Hosseini, H. Improving the Barrier Properties of Food Packaging by $\mathrm{Al}_{2} \mathrm{O}_{3} @ \mathrm{TiO}_{2}$ \& $\mathrm{Al}_{2} \mathrm{O}_{3} @ \mathrm{SiO}_{2}$ Nanoparticles. Food Bioprocess Technol. 2021, 14, 1287-1300.

36. Pierre, A.C. Introduction to Sol-Gel Processing, 2nd ed.; Pierre, A.C., Ed.; Springer: Berlin/Heidelberg, Germany, 2020.

37. Licciardello, F.; Piergiovanni, L. Packaging and food sustainability. In The Interaction of Food Industry and Environment; Galanakis, C., Ed.; Academic Press: Cambridge, MA, USA, 2020; pp. 191-222.

38. Hubbe, M.A.; Gardner, D.J.; Shen, W. Contact Angles and Wettability of Cellulosic Surfaces: A Review of Proposed Mechanisms and Test Strategies. BioResources 2015, 10, 8657-8749. [CrossRef]

39. George, B.; Suttie, E.; Merlin, A.; Deglise, X. Photodegradation and photostabilisation of wood-The state of the art. Polym. Degrad. Stab. 2005, 88, 268-274. [CrossRef]

40. Sha, L.; Ma, C.; Zhao, H.; Qiu, S.; Yan, Z.; Guo, D. Facile fabrication of superhydrophobic filter paper with improved durability and water repellency. Nord. Pulp Pap. Res. J. 2021. [CrossRef]

41. Cogulet, A.; Blanchet, P.; Landry, V. Wood degradation under UV irradiation: A lignin characterization. J. Photochem. Photobiol. B Biol. 2016, 158, 184-191. [CrossRef]

42. Sadeghifar, H.; Ragauskas, A. Lignin as a UV Light blocker-a review. Polymers 2020, 12, 1134. [CrossRef] [PubMed]

43. Taboada-Rodríguez, A.; García-García, I.; Cava-Roda, R.; López-Gómez, A.; Marín-Iniesta, F. Hydrophobic properties of cardboard coated with polylactic acid and ethylene scavengers. J. Coat. Technol. Res. 2013, 10, 749-755. [CrossRef] 